\title{
Palma entre jóvenes
}

\author{
GLADYS FLORES HEREDIA \\ Universidad Ricardo Palma \\ Lima, Perú \\ Contacto: gladys.floresh@urp.edu.pe
}

La agenda de efemérides registró el año 2019 dos acontecimientos bastante significativos para los peruanos y para la comunidad académica de nuestra universidad, y es que por un lado se conmemoraron los cien años del fallecimiento de don Ricardo Palma (1833-1919) y, por otro lado, se celebraron los cincuenta años de fundación de nuestra casa de estudios, la Universidad Ricardo Palma (1969-2019).

Son numerosas las actividades que se realizaron en todo el Perú para recordar la vigencia y la actualidad de nuestro insigne tradicionista, autor de una de las obras más completas, en la que supo atrapar y conservar las tradiciones populares y la memoria urbana sobre el periodo colonial y republicano, me refiero a las Tradiciones peruanas (1872-1917), a la que le siguen las obras Monteagudo $y$ Sánchez Carrión. Páginas de la historia de la independencia (1877) y Refutación a un compendio de historia del Perú (1886), así como también sus meditaciones sobre el uso particular que se hace del 
español en tierras americanas: Neologismos y americanismos (1896) y Dos mil setecientas voces que hacen falta en el Diccionario. Papeletas lexicográficas (1903).

No se equivocaba nuestro Premio Nobel de Literatura cuando allá por la década del cincuenta propuso que comprendamos la obra de Palma como aquella cuya influencia había logrado traspasar el plano literario para instalarse como «huella perdurable en el espíritu nacional» (Vargas Llosa, 2014, p. 27). Y es así como se ha evaluado la obra de Palma hasta la actualidad: como aquella que a través del humor y la ironía mantiene un diálogo ininterrumpido con el presente y el pasado; una obra que interpreta de manera magistral «la psicología y el alma de toda una época» (Vargas Llosa, 2014, p. 30).

Cuando se examinan los programas de los eventos realizados en torno a Palma, se puede advertir que la mayoría de ellos reúne a especialistas en el estudio de la amplia obra de Palma, entre críticos literarios e historiadores. Sin embargo, no se han organizado aún certámenes que convoquen exclusivamente a los estudiantes universitarios de distintas carreras académicas que conversen y propongan cómo se relacionan y qué es lo que les sugiere el legado intelectual de Ricardo Palma en estas primeras décadas del siglo XXI, y en un contexto global orientado por el consumismo del mercado, la comunicación electrónica, el libro digital y las cada vez más aceleradas transformaciones de la sensibilidad y las crisis medioambientales.

Para conocer las formas de percepción y aprehensión que tiene la obra de Palma en los alumnos de nuestra casa de estudios es que se propuso la organización del «I Coloquio de Estudiantes Universitarios Ricardo Palma 2019», evento que logró reunir a estudiantes de diversas facultades que expusieron, desde su experiencia y su formación, el entendimiento que tienen sobre la obra de nuestro escritor emblema nacional. 
La revista El Palma de la Juventud se divide en cinco apartados, cada uno organizado como dossier. El primero tiene como título «Reflexiones desde la Arquitectura sobre las Tradiciones peruanas», en este se reúnen los artículos de dos alumnas de la Facultad de Arquitectura y Urbanismo: Acosta y Romucho. La perspectiva que ellas tienen sobre Palma está centrada en las descripciones e informaciones que las tradiciones proveen tanto sobre la arquitectura colonial como la republicana, así también se preguntan sobre la imagen que estas proyectan a propósito de la figura del arquitecto. Se debe destacar que se trata de planteamientos que nos hacen ver la presencia de la obra de Palma, sus Tradiciones fundamentalmente, no solo como narraciones de divertimiento, sino como historias que tienen vida arquitectónica fuera de los textos. De hecho, las aproximaciones que realizan las alumnas tienen este aspecto positivo: logran hacer dialogar el texto palmiano con la realidad y con la actualidad de su formación disciplinaria. Así, consiguen extraer del pasado la lección para conducirse por el presente. También resitúan los contenidos de las Tradiciones en el siglo XXI y en contextos disciplinarios no exclusivamente propios del campo literario.

La figura del médico, la medicina y la ciencia es el otro núcleo que articula algunas intervenciones del dossier «La presencia de la Medicina y las ciencias en las Tradiciones peruanas». Sus autores, los alumnos Rivera, Butrón, Medina, Hualpa, Beltrán y Bedoya, plantean acercamientos bastante interesantes y diversos: desde las reflexiones de Palma sobre la «quina», la herbolaria y la medicina tradicional, pasando por el rol del médico y la implicancia que sus decisiones tienen para la salud pública. Ciertamente Palma exige la responsabilidad y el profesionalismo a los médicos cuando estos ejercen sus funciones.

Los estudiantes de la carrera de Psicología se interesaron por la presentación de los personajes con patologías conductuales que aparecen en las Tradiciones. El detalle descriptivo con que 
Palma presenta a varios personajes sirvió para que los alumnos Villanueva y Esquivel propongan sus reflexiones sobre los trastornos psicológicos, la psicología femenina y el complejo funcionamiento de los mecanismos lógicos e ilógicos, conscientes e inconscientes de la mente, los cuales se reúnen en el tercer dossier titulado "Análisis psicológicos de algunos personajes de las Tradiciones peruanas». Lo mismo hicieron las estudiantes universitarias de la carrera de Ingeniería Civil: Ferrari y Gonzales, quienes analizaron los espacios de la ciudad, la presencia de edificaciones y el bienestar que estos producen en el dossier «La Ingeniería en las Tradiciones peruanas».

Hasta donde venimos explicando, los estudiantes han logrado establecer puntos de contacto con las Tradiciones de Palma. Esta amplia posibilidad nos informa sobre la riqueza de componentes disciplinarios que están contenidos en los textos palmianos. Si tenemos la percepción desde la Arquitectura, la Medicina, la ciencia y la Ingeniería, estas se complementarán con otras aproximaciones interdisciplinarias. Es por ello que el quinto dossier, «La obra de Palma y las aproximaciones interdisciplinarias», plantea la interacción con otros campos del saber. Es el apartado donde las tradiciones se enfocan como textos, es decir, las ponencias buscan explicar los componentes lingüísticos, literarios, jurídicos, pedagógicos, sociales y culturales que poseen las obras. Se trata de artículos que se preguntan sobre la presentación de grupos sociales escindidos, las cuestiones pedagógicas y las reflexiones culturales. En efecto, estos textos muestran que las Tradiciones de Palma no han perdido la actualidad, pues las reflexiones que proponen Zegarra, Pauca, Huamán, López, Lara y Morales así nos lo hacen saber.

Ricardo Palma tuvo interés por la historia y por la literatura. Acaso por ello es que creó el género tradición, narración que combina elementos ficcionales de la literatura con aquellos otros que provienen de los hechos acaecidos en la historia. Por ese motivo, varias de las 
Tradiciones están ambientadas y directamente relacionadas con momentos históricos claros y con personajes completamente definidos de la historia nacional (incas, virreyes y libertadores). Este rasgo fue advertido por los alumnos cuyos trabajos integran el último dossier, sus artículos explican las costumbres coloniales en las Tradiciones, así como las raíces de la desigualdad social, la deshumanización, la corrupción y lo que significa lo peruano para Palma.

Este apretado recuento de las líneas de trabajo que proponen cada uno de los artículos presentados para este primer número de la revista, fue seleccionado tras someterse a una evaluación de revisores pares externos. El conjunto de estos textos nos informa que las Tradiciones peruanas de Palma poseen contenidos cognoscitivos y estéticos que no obstante el paso del tiempo aún continúan llamando la atención de nuevos lectores. Siempre que oigo decir que «los jóvenes no leen» o que «los jóvenes no leen ni a los escritores actuales, menos van a leer a los clásicos», me pregunto qué hemos hecho como profesores para acercar a los jóvenes hacia los clásicos de nuestra literatura peruana. Considero que no debemos atribuir la responsabilidad de aquel presunto alejamiento solo a los jóvenes, pues también tenemos algo que ver en ello. Efectivamente, algunos de nosotros hemos olvidado enseñar a dialogar e interactuar desde nuestro presente y con nuestras preguntas contemporáneas con aquellos autores que forman el gran corpus de la literatura clásica nacional. Hemos olvidado que autores como el Inca Garcilaso de la Vega, Ricardo Palma, Manuel González Prada y José Carlos Mariátegui tienen para nuestro presente algunas ideas sobre las que podríamos conversar. Por ello, nuestra pedagogía de la lectura debe invitar a aprender a dialogar con nuestros escritores del pasado, y cuando decimos dialogar, debe entenderse que no se dialoga sin que antes no se aprenda a comprender, interpretar, criticar, valorar y producir textos académicos. 
La publicación del primer número de la revista de estudiantes $E l$ Palma de la Juventud es una muestra del diálogo que ha realizado y plasmado por escrito el amplio grupo de alumnos de las distintas facultades que conforman nuestra universidad, un diálogo fomentado desde los cursos del Taller de Comunicación Oral y Escrita I y II, continuada y reforzada a través de los talleres de escritura de artículos académicos que desarrollé de cara a la realización del «I Coloquio de Estudiantes Universitarios Ricardo Palma 2019».

Cabe mencionar que en este taller, al que asistieron muchos de los alumnos que han participado en el coloquio, se brindaron las indicaciones principales sobre cómo debían estructurar su artículo, citar a diversos especialistas que refuercen su investigación, desarrollar sus ideas centrales citando un fragmento de la tradición analizada y aplicar correctamente las referencias en el formato APA, abreviatura que se usa para referirse al Manual de publicaciones de la American Psychological Association. De manera análoga, se dieron pautas para su participación, todo ello con el objetivo de afianzar las destrezas de la comunicación oral. En una segunda etapa de este taller, se les pidió a los estudiantes que envíen sus artículos por correo, para así revisarlos con control de cambios y colocarles notas en las que se les pedía que completen las referencias, reescriban algunas ideas con mayor claridad o profundicen algunos temas relevantes. En ese sentido, aquellos alumnos que asistieron al taller reforzaron sus conocimientos sobre los aspectos relevantes de todo texto académico, pues a través de las correcciones y observaciones que se les hacía, y que posteriormente enmendaron, aprendieron a tener en cuenta los elementos indispensables que no deben faltar en un artículo. Para el caso de los alumnos que no asistieron a los talleres, sus textos fueron corregidos y adecuados para su publicación.

No dudamos de que el transcurrir del tiempo y la adquisición de nuevos conocimientos y experiencias universitarias harán que estos 
artículos de iniciación académica de nuestros jóvenes alumnos, muchos de ellos «cachimbos», alcancen profundidad, pues estoy segura de que más de uno enriquecerá su conocimiento sobre la obra de Palma. Ténganse, en tal sentido, este primer número de El Palma de la Juventud no solo como el archivo o documentación escrita para que otras generaciones de estudiantes evalúen el legado de Ricardo Palma, sino también como una publicación que guarda la memoria de un conjunto de estudiantes que se atrevieron a pensar en la obra de Palma desde el marco de su formación disciplinaria.

Para finalizar, quiero agradecer al rector de nuestra universidad, el doctor Iván Rodríguez Chávez, quien desde un inicio respaldó la gestación y concreción de este proyecto, pues está convencido, como nosotros, de que un estudiante universitario, desde el primer año, tiene que formar parte del debate académico a través de su participación en este tipo de publicaciones institucionales.

\section{REFERENCIA}

Vargas Llosa, M. (2014). Palma, valor nacional. En Palma, R. Tradiciones peruanas. Primera y segunda series (M. Á. Rodríguez Rea, ed.; pp. 27-30). Universidad Ricardo Palma, Editorial Universitaria. 